\title{
Hepatocellular carcinoma and African iron overload
}

\author{
I T Gangaidzo, V R Gordeuk
}

\begin{abstract}
Both hepatocellular carcinoma (HCC) and iron overload are important health problems in Africa. Chronic hepatitis B virus (HBV) infection is recognised as a major risk factor for HCC, but iron overload in Africans has not been considered in pathogenesis. Up to half the patients with HCC in Africa do not have any recognised risk factors such as preceding chronic HBV infection, and other risk factors remain unidentified. HCC is an important complication of HLA-linked haemochromatosis, an iron loading disorder found in Europeans. It is proposed that African iron overload might also be a risk factor for HCC.

(Gut 1995; 37: 727-730)
\end{abstract}

Keywords: hepatocellular carcinoma, iron, epidemiology.

Although the annual incidence of hepatocellular carcinoma (HCC) is low in North America and western Europe, it is probably the most common malignancy occurring in men worldwide. ${ }^{1}$ The highest incidence of 100 cases per 100000 of population annually has been reported in the southern African country of Mozambique. ${ }^{2}$ The association of $\mathrm{HBV}$ infection and HCC in Africa is widely recognised, ${ }^{3}$ while exposure to aflatoxins ${ }^{45}$ and alcohol $^{6}$ are also possible aetiological factors. Longtime investigators in the field are convinced that other as yet unidentified associations must exist. ${ }^{7}$ Cirrhosis of various causes is recognised to be important in the aetiology of HCC. ${ }^{1}$ Cirrhosis secondary to $\mathrm{HBV}$ is regarded as the most important risk factor in Africa, China, and South East Asia, ${ }^{38}$ while alcoholic cirrhosis seems to be more important in North America and western Europe. ${ }^{9}$ Cirrhosis secondary to primary biliary cirrhosis, autoimmune chronic active hepatitis, chronic hepatitis C infection, and HLA-linked haemochromatosis are also associated with the development of $\mathrm{HCC}^{1}{ }^{1}$ While it has been well reported that iron overload in Africans is an important cause of cirrhosis, ${ }^{1011}$ this condition has not been regarded as part of the aetiology of HCC in Africa. ${ }^{112}$ We review evidence that suggests that iron overload may contribute to the high incidence of HCC in Africa.

Correspondence to: Dr I T Gangaidzo Department of Medicine, University of Zimbabwe, PO Box A178 Avondale, Harare, Zimbabwe.

Accepted for publication 11 April 1995

\section{More than just hepatitis $B$}

Studies in epidemiology, comparative pathology, and molecular biology have consistently shown a strong association between persistent
HBV infection and subsequent development of HCC. ${ }^{1313}$ In sub-Saharan Africa $80 \%$ of persons acquire $\mathrm{HBV}$ infection by the age of 10 years, and of those infected about $20 \%$ become chronic carriers. ${ }^{1415}$ Similar HBV prevalence rates apply to Asia. ${ }^{8}$ Despite these very high rates of endemicity, and the strong relation between HBV infection and the development of HCC, the reasons why only a small number of people with persistent $\mathrm{HBV}$ infection develop HCC are not known.

In South East Asia chronic HBV infection accounts for most of the cases of HCC. By contrast, in Africa, a considerable proportion of HCC is not explicable on this basis. Two particularly well performed studies illustrate this point. In 1975, a prospective study in Taiwan looked at 22707 male Chinese to evaluate the incidence of HCC and its association with $\mathrm{HBV}$ infection. ${ }^{8}$ Of these subjects, $3454(15 \%)$ were found to be carriers. Follow up to December 1986 showed excess deaths from $\mathrm{HCC}$ in the $\mathrm{HB}_{\mathrm{s}} \mathrm{Ag}$ positive subjects. Of the 152 who died of HCC, 143 were carriers. Only nine of the original 19253 who were $\mathrm{HB}_{\mathrm{s}} \mathrm{Ag}$ negative developed $\mathrm{HCC}$. The evidence from Africa is different. In a case controlled study of 140 adults and their 603 family contacts in the Gambia, only $53 \%$ of all cases of hepatoma could be attributed to persistent HBV infection. ${ }^{15}$ Similar findings have been reported in southern Africa, where only 18 to $44 \%$ of patients with HCC have evidence of persistent $\mathrm{HB}_{\mathrm{s}} \mathrm{Ag}$ in non-malignant hepatic tissue $^{1216}$ and only 29 to $58 \%$ have such evidence in serum assays. ${ }^{712}$ Furthermore, the risk estimates between persistent HBV infection and development of HCC show wide variation within Africa. ${ }^{17}$ These findings would suggest the existence of different susceptibility levels for the development of HCC in the face of chronic HBV infection or different exposure rates to other carcinogens, particularly in the African population. ${ }^{15} 1718$

HLA-linked haemochromatosis and HCC Although iron is essential for life, iron overload is toxic and potentially fatal. The liver is an important site of iron storage and is particularly susceptible to injury in iron overload. This liver damage is particularly evident in homozygous HLA-linked haemochromatosis, one of the most common inherited disorders in European populations with a prevalence of up to $0.45 \% .{ }^{19}$ The disease is characterised by increased intestinal iron absorption and progressive parenchymal iron overload. The affected subjects typically show clinical symptoms of parenchymal organ damage including 
cirrhosis after the third to fourth decades of life and they have a considerably increased risk of developing $\mathrm{HCC}^{20}$ The pathogenesis of $\mathrm{HCC}$ in HLA-linked haemochromatosis and the role of hepatic iron overload, in particular, are uncertain. Iron has been shown to be mutagenic and might directly initiate carcinogenesis in the liver. ${ }^{21}$ In vitro, iron enhances and the withholding of iron inhibits the growth of human hepatoma cell lines. ${ }^{22}$ Support for a direct carcinogenic effect of iron is provided by the finding that patients with HLA-linked haemochromatosis who are most likely to develop HCC have the highest mobilisable iron concentrations. ${ }^{20}$ Alternatively, excessive hepatic iron may play an indirect part in the multi-step process of malignant transformation by inducing hepatocellular damage and cirrhosis.

Until recently, all reported cases of HCC complicating HLA-linked haemochromatosis had arisen in cirrhotic livers, and patients without cirrhosis were not considered at increased risk. Early diagnosis and repeated venesection of patients with HLA-haemochromatosis were believed to prevent malignant transformation by preventing tissue iron accumulation, which causes hepatic damage and ultimately, cirrhosis. $^{2023}$ Several investigations have now reported the development of HCC in patients with HLA-linked haemochromatosis who do not have cirrhosis. ${ }^{24} 25$ Fellows and colleagues described two patients with primary haemochromatosis but not cirrhosis in whom HCC supervened despite removal of excess iron by venesection therapy. ${ }^{24}$ In another report a 67 year old man with a 32 year history of HLA-linked haemochromatosis complicated by cirrhosis had reversal of cirrhosis with phlebotomy therapy yet developed HCC. ${ }^{25}$ The occurrence of HCC in non-cirrhotic patients with HLA-linked haemochromatosis is compatible with a possible direct carcinogenic effect of iron.

\section{African iron overload and HCC}

Severe iron overload is common in subSaharan Africa, achieving a prevalence of more than $10 \%$ in some populations. ${ }^{26} 27$ The condition has been most frequently reported and best recorded in southern Africa ${ }^{262829}$ where the prevalence of HCC is also higher than in the rest of the continent. ${ }^{2} 30$ Iron overload, however, has been reported in all regions of sub-Saharan Africa including Tanzania and Uganda in east Africa, ${ }^{31} 32$ and Ghana and Nigeria in west Africa. ${ }^{33} 34$ Iron overload in Africa is related to the consumption of a traditional fermented beverage with high iron content. ${ }^{29}$ The consumption of this type of beer occurs in east and west Africa (Hakim J, Okwanga $\mathrm{N}$, personal communications), but has been best described in southern Africa. ${ }^{29}$ While African iron overload has been perceived as having a purely environmental aetiology (excessive dietary iron present in traditional beer), recent evidence points to an interaction between the amount of dietary iron and a possible non-HLA-linked iron loading gene as being potentially important in pathogenesis. ${ }^{35}$ This form of iron overload is characterised pathologically by massive deposition of iron in both macrophages and hepatocytes, and subsequently by fibrosis and cirrhosis. ${ }^{10} 12$

While hepatic concentrations of iron in African iron overload commonly rival those found in HLA-linked haemochromatosis, ${ }^{27}$ an association between HCC and this common African form of iron overload is not widely recognised. ${ }^{112}$ One reason for this lack of recognition is that certain publications from the 1950 s and 1960s influenced medical practitioners and investigators to disregard African iron overload as a factor in the aetiology of HCC. ${ }^{36-38}$ These papers, referring to work performed in South Africa, put forth the assertion that there is no convincing evidence for an association between siderosis and HCC. If you consider the studies upon which this opinion was based, ${ }^{39-41}$ you are struck by the paucity of data actually tackling the issue and left with the conclusion that the question of an aetiological relation between African iron overload and HCC was not adequately investigated at that time.

Another reason that African iron overload has been regarded as fairly benign, when compared with HLA-linked haemochromatosis, is that a large proportion of the excess iron is in macrophages of the reticuloendothelial system $^{10}$ where it is thought to be comparatively harmless. ${ }^{42}$ This fact has led to the misconception among some health professionals that all excess iron is in the reticuloendothelial system. Several considerations support the concept that the pathogenesis of iron-loading and the details of the histological distribution of iron in HLA-linked haemochromatosis and African iron overload differ. Iron loading in HLA-linked haemochromatosis occurs because a genetic defect leads to excessive iron absorption from a diet with normal iron content, ${ }^{43}$ whereas in the African condition iron overload generally develops in subjects who consume a diet with high amounts of bioavailable dietary iron $^{29}$ and possibly have a different genetic defect. ${ }^{35}$ Furthermore, iron loading in HLAlinked haemochromatosis is predominantly parenchymal, whereas iron accumulation in African iron overload is prominent in macrophages as well as in hepatic parenchymal cells. ${ }^{44} 45$ The point to be emphasised here is that iron loading of hepatocytes is a feature that is common to both African iron overload and HLA-linked haemochromatosis. Early descriptions of the histology of African iron overload clearly showed that hepatocytes may be as severely affected by iron loading as macrophages. Furthermore, a substantial proportion of patients with the African condition have iron loading that extends to other organs in a manner similar to HLA-linked haemochromatosis. ${ }^{28}$

A third reason that African iron overload has been regarded as comparatively non-toxic is the concept that serum iron and transferrin saturation concentrations are generally normal in this condition, becoming increased only after the condition is advanced and cirrhosis 
develops. ${ }^{23}$ Recent studies have shown that high serum iron concentrations are common in African iron overload, ${ }^{2646}$ and that the transferrin saturation may be considerably increased in non-cirrhotic subjects. ${ }^{47}$ An abnormal non-transferrin bound iron fraction has been described in the plasma of patients with other iron overload conditions marked by a high transferrin saturation and could be expected to occur in patients with the African condition also. Such an abnormal iron fraction might lead to toxicity through the formation of reactive oxygen species. ${ }^{48} 49$

The cytopathogenic mechanisms of hepatocellular damage in iron overload conditions remain unclear. ${ }^{50}$ Possible pathways include the presence in parenchymal cells of iron in excess of capacity for safe storage in ferritin and haemosiderin leading to the generation of toxic free radicals such as the hydroxyl radical. ${ }^{51}$ Because both African iron overload and HLA-linked haemochromatosis may be marked by parenchymal iron loading and high transferrin saturation, it seems plausible to postulate that excessive deposition of iron in African iron overload, as in HLA-linked haemochromatosis, will lead not only to cirrhosis but to the development of HCC. Italian investigators have suggested that excess iron facilitates persistent $\mathrm{HBV}$ and hepatitis $\mathrm{C}$ virus $(\mathrm{HCV})$ infection and could act as a cofactor in the pathogenesis of HCC in patients with viral hepatitis. ${ }^{52}$ Evidence showing that the iron chelator desferrioxamine inhibits $\mathrm{HBV}$ virion replication in vitro ${ }^{53}$ is in keeping with the possibility that iron may directly activate HBV multiplication.

The hypothesis that iron overload in Africans is a risk factor for HCC has never been formally tested, but several reports have appeared that provide potentially supportive data. (1) In Strachan's original necropsy series describing iron overload in Africans in 1929, 10 of $114(8.8 \%)$ subjects with considerably increased hepatic iron concentrations died from hepatoma compared with one of 159 $(0 \cdot 6 \%)$ subjects with normal hepatic iron. ${ }^{28}(2)$ In a study of HCC tumour morphology conducted in 90 subjects of rural and urban origins in Johannesburg, South Africa, in the early 1980 s, iron content was graded in non-malignant liver tissue. The prevalence of severe hepatic iron overload (defined as grade 3-4/4 hepatocellular iron) was $33 \cdot 2 \%,{ }^{12}$ or twice the prevalence of iron overload (tissue iron concentration $>180 \mu \mathrm{mol} / \mathrm{g}$ dry weight) in a necropsy series of black Africans dying of all causes from the same institution. ${ }^{46}$ (3) In a recent rural based study in the Transkei, South Africa, 203 biopsy specimens of non-malignant liver tissue from 246 patients with HCC were evaluated. Cirrhotic livers were diagnosed in $45.1 \%$ and severe haemosiderosis in $45 \%$; the presence of both cirrhosis and severe haemosiderosis was found in $38 \%$ of the specimens. ${ }^{16}$ Although the hypothesis that iron overload is a risk factor for the development of HCC was not formally tested, the high proportion of $45 \%$ of patients with severe siderosis and $38 \%$ of patients with coexistent severe iron overload and cirrhosis is striking. For comparison, evidence for severe iron overload on the basis of high transferring saturation and ferritin values was found in approximately $16 \%$ of male traditional beer drinkers in a rural community in South Africa in the late 1980's. ${ }^{46}$

Thus several studies examining hepatic iron content in subjects with HCC in southern Africa have consistently found high prevalences of severe iron overload that are greater than in the background populations. These findings are consistent with the hypothesis that African iron overload is a risk factor for the development of HCC. This aetiological association could be indirect, with iron overload leading to the development of cirrhosis and subsequent HCC. Secondly, hepatocellular iron may have a direct carcinogenic effect. Finally, hepatocellular iron might favour chronic $\mathrm{HBV}$ or $\mathrm{HCV}$ infection and thus serve as a co-carcinogen with chronic viral hepatitis in the development of HCC.

In conclusion, a substantial proportion of HCC in Africa does not seem to be accounted for by chronic HBV infection. Other aetiological factors are involved and some remain to be identified. Iron overload in HLA-linked haemochromatosis is recognised as an aetiological factor in the development of HCC. African iron overload may be one of the currently unrecognised risk factors for HCC in Africa, as evidenced by the finding in several series that hepatocellular iron overload is more common in subjects with HCC than in the general population. If African iron overload is an aetiological factor for HCC, it is eminently preventable through changing the practices of preparation and consumption of traditional beer, and it is treatable by phlebotomy therapy to remove iron from the body. We propose that prospective studies should be undertaken to examine the possible role of African iron overload in the pathogenesis of HCC.

This study was supported in part by National Institute of Child Health and Human Development Contract NO1-HD-3-3196 by the grant from the Office of Minority Health to the Cell Biology and Metabolism Branch, National Institute of Child Health and Human Development, Bethesda, MD, USA; the Research Board, University of Zimbabwe; and by a grant from the J F Kapnek Charitable Trust, and Mrs Podmore, librarian at the UZ School of Medicine.

1 Rustigi VK. Epidermiology of hepatocellular carcinoma. Gastroenterol Clin North Am 1987; 16: 545-51.

2 Van der Merwe. Primary liver cancer in South Africa. A review. Gastroenterology Forum 1990; 1: 7-16.

3 Kew MC, Desmyter J, Bradburne AF, Macnab GM Hepatitis B virus infection in Southern African Blacks with hepatocellular carcinoma. $\mathcal{F}$ Natl Cancer Inst 1979; 62: 517-20.

4 Peers F, Bosch X, Kaldor J, Linsell CA, Pluijmen $M$. Aflatoxin exposure, hepatitis $B$ virus infection and liver cancer in Swaziland. Int $\mathcal{f}$ Cancer 1987; 39: 545-53.

5 Lutwick LI. Relationship between aflatoxin, hepatitis B virus, and hepatocellular carcinoma. Lancet 1979; i: 755-7.

6 Mohamed A, Kew MC, Groeneveld HT. Alcohol consumption as a risk factor for hepatocellular carcinoma in urban South African Blacks. Int $\mathcal{F}$ Cancer 1992; 51: 537-41.

7 Kew MC. Hepatocellular carcinoma with and withou cirrhosis: a comparison in southern African blacks. Gastroenterology 1989; 97: 136-9.

8 Beasley RP, Hwang L-Y, Lin CC, Chien CS Hepatocellular carcinoma and hepatitis B virus - A prospective study of 22707 men in Taiwan. Lancet 1981 2: $1129-33$.

9 Leevy CM, Gellene R, Ning M. Primary liver cancer in cirrhosis of the alcoholic. Ann NY Acad Sci 1964; 114: 
10 Bothwell TH, Bradlow BA. Siderosis in the Bantu. A combined histopathological and chemical study. Arch Pathol 1960; 70: 279-92.

11 Isaacson C, Seftel HC, Keeley KJ, Bothwell TH. Siderosis in the Bantu: the relationship between iron overload and cirrhosis. F Lab Clin Med 1961; 58: 845-53.

12 Paterson AC, Kew MC, Herman AAB, Becker PJ, Hodkinson J, Isaacson C. Liver morphology in Southern African Blacks with hepatocellular carcinoma: a study within an urban environment. Hepatology 1985; 5: 72-8.

13 Dusheiko G. Hepatocellular carcinoma: molecular biology, etiology and animal model. Gastroenterol Clin North Am 1987; 16: 575-89.

14 Barrin F, Perrin J, Chortard J, Denis F, N'Doye R, Diop Mar I, et al. Cross-sectional and longitudinal epidemiology of hepatitis B in Senegal. Prog Med Virol 1981; 27: 148-62.

15 Kew MC, Rossouw E, Hodgkinson HJ. Hepatitis B virus status of southern African Blacks with hepatocellular carcinoma: comparison between rural and urban patients. Hepatology 1983; 3: 65-8.

16 Jaskiewicz K, Stephen A, Banach L. Hepatocellular carcinoma in a rural population at risk. Anticancer Res 1991; 11: 2187-90.

17 Ryder RW, Whittle HC, Sanneth AB, AIdukiewicz AB, Tulloch S, Yvonnet B. Persistent hepatitis B virus infection and hepatoma in the Gambia, West Africa. A casecontrolled study of 140 adults and their 603 family contacts. Am f Epidemiol 1992; 136: 1122-31.

18 Larouze B, Blumberg BS, London WT, Lustbader ED, Sankale M, Payet M. Forecasting the development of primary hepatocellular carcinoma by the use of risk primary hepatocellular carcinoma by the use of risk 58: $1557-61$.

19 Edwards CQ, Griffen LM, Goldgar D, Drummond C, Skolnick MH, Kushner JP. Prevalence of hemochromatosis among 11,065 presumably healthy blood donors. N Engl $₹$ Med 1988; 318: 1355-62.

20 Nierderau C, Fischer R, Sonnenberg A, Stremmel W, Trampisch HJ, Strohmeyer G, et al. Survival and causes of death in cirrhotic and in noncirrhotic patients with primary hemocromatosis. $N$ Engl $\mathcal{f}$ Med 1985; 313: 1256-62.

21 Loeb LA, James EA, Waltersdorph AM, Klebanoff SJ. Mutagenesis by the autoxidation of iron with isolated DNA. Proc Natl Acad Sci USA 1988; 85: 3918-22.

22 Hann HWL, Stahlhut MW, Hann L. Effect of iron and desferoxamine on cell growth and in vitro ferritin synthesis in human hepatoma cell lines. Hepatology 1990; 11: 566-9.

23 Bothwell TH, Charlton RW, Cook JD, Finch CA. Iron metabolism in man. Oxford: Blackwell Scientific, 1979.

24 Fellows IW, Stewart M, Jeffcoate WJ, Smith PG, Toghil PJ. Hepatocellular carcinoma in primary haemachromatosis in the absence of cirrhosis. Gut 1988; 29: 1603-6.

25 Blumberg RS, Chopra S, Ibrahim R, Crawford J, Farraye FA, Zeldis JB, et al. Primary hepatocellular carcinoma in idiopathic hemochromatosis after reversal of cirhosis. Gastroenterology 1988; 95: 1399-402.

26 Gordeuk VR, Boyd RD, Brittenham GM. Dietary iron overload persists in rural sub-Saharan Africa. Lancet 1986; i: 1310-3.

27 Gordeuk VR. Hereditary and nutritional iron overload. Baillieres Clin Haematol 1992; 5: 169-86.

28 Strachan AS. Haemosiderosis and haemochromatosis in South African Natives with a comment on Etiology of haemochromatosis [thesis]. Glasgow: University of Glasgow, 1929.

29 Bothwell TH, Seftel H, Jacobs P. Iron overload in Bantu subjects. Studies on the availability of iron in Bantu beer. Am $\mathcal{F}$ Clin Nutr 1964; 14: 47-51.
30 Olweny C. Cancer. In: Parry EO, ed. Principles of medicine in Africa. 2nd ed. Oxford: Oxford University Press, 1984: 973-93.

31 Haddock DRW. Bantu siderosis in Tanzania. E Afr Med $\mathcal{f}$ 1965; 42: 67-71.

32 Owor R. Haemosiderosis in Uganda: Autopsy study. East Afr Med F 1974; 51: 388-91.

33 Dodu SRA. Diabetes and haemosiderosis - haemochromatosis - in Ghana. Trans $R$ Soc Trop Med Hyg 1958; 52: 425-31.

34 Isah HS, Fleming AF. Anaemia and iron status of symptom-free adult males in northern Nigeria. Ann Trop Med Parasitol 1985; 79: 479-84.

35 Gordeuk V, Mukiibi J, Hasstedt SJ, Samowitz W, Edwards $\mathrm{CQ}$, West G, et al. Iron overload in Africa - interaction between a gene and dietary iron content. $N$ Engl $\mathcal{F}$ Med 1992; 326: 95-100.

36 Higginson J. The geographic pathology of primary liver cancer. Cancer Res 1963; 23: 1624-33.

37 Higginson J. Primary carcinoma of the liver in Africa. $\mathrm{Br} F$ Cancer 1956; 10: 609-22.

38 Higginson J. Pathogenesis of liver cancer in the Johannesburg area (S Africa). Acta-Unio Internationalis Contra Cancrum 1957; 13: 590-8.

39 Higginson J, Gerritsen T, Walker ARP. Siderosis in the Bantu of Southern Africa. Am F Pathol 1953; 29: 779-815.

40 Higginson J, de Meillon B. Schistosoma haematobium infestation and hepatic disease in man. Arch Pathol 1955; 60: $341-6$.

41 Butt EM, Higginson J. Trace element pattern in liver disease and liver carcinoma. Acta-Unio Internationalis disease and liver carcinoma. Acta-
Contra Cancrum 1957; 13: 599-601.

42 Hershko C. Storage iron regulation. Prog Haematol 1977; 10: $105-48$.

43 Whittaker P, Skikne BS, Covell AM, Flowers C, Cooke A, Lynch SR, et al. Duodenal iron proteins in idiopathic hemochromatosis. F Clin Invest 1989; 83: 261-7.

44 Bothwell TH, Abrahams C, Bradlow BA, Charlton RW Idiopathic and Bantu hemochromatosis. Arch Pathol 1965; 79: 163-8.

45 Brink B, Disler P, Lynch S, Jacobs P, Charlton R, Bothwell $T$. Patterns of iron storage in dietary iron overload and idiopathic hemochromatosis. $\mathcal{f}$ Lab Clin Med 1976; 88: 725-31.

46 Friedman BM, Baynes RD, Bothwell TH, Gordeuk VR, Macfarlane BJ, Camparelli RD, et al. Dietary iron overload in southern African rural blacks. S Afr Med F 1990; 78: $301-5$

47 Bloom P, Gordeuk VR, Barry M, Phiri B, Paterson A, MacPhail AP. Increased transferrin saturation in an African with iron overload but with no cirrhosis. Blood 1993; 82: 432a.

48 Gutteridge JM, Rowley DA, Griffiths E, Halliwell B. Low molecular weight iron complexes and oxygen radical reactions in idiopathic haemochromatosis. Clin Sci 1985; 68: 463-7.

49 Hershko C, Graham G, Bates GW, Rachmilewitz EA. Nonspecific serum iron in thalassaemia: an abnormal serum iron fraction of potential toxicity. Br f Haematol 1978; 40: iron fraction $255-63$.

50 Gordeuk VR, McLaren GD, Samowitz Wade. Etiologies, consequences and treatment of iron overload. Crit Rev Clin Lab Sci 1994; 31: 89-133.

51 Halliwell B, Gutteridge JMC, Cross CE. Free radicals, antioxidants, and human disease. $\mathcal{F}$ Lab Clin Med 1992; 119: 598-620.

52 Fargion S, Piperno A, Fracanzani AL, Cappellini MD, Romano R, Fiorelli G. Iron in the pathogenesis of hepatocellular carcinoma. Ital f Gastroenterol 1991; 23: 584-8.

53 Schwarz, Korba. Desferioxamine (DF) inhibits hepatitis B virus (HBV) virion production by HEP G2 (2.2.15) cells. Hepatology 1990; 12: 972. 